\title{
[ALUR PELAYANAN PASIEN RAWAT INAP DI RUMAH SAKIT EMANUEL]
}

\author{
NPM $\quad: 19411040$ \\ NAMA :RICHA ISMI RENDA \\ PRODI :SISTEM INFORMASI \\ FAKULTAS :ILMU KOMPUTER \\ EMAIL_:ismirendaricha@gmail.com
}

\section{SOAL TUGAS :}

Buatlah Program dengan ketentuan sebagai berikut : Input :

kode pasien $=$ PS0003

Kode Kamar $=4444$

Lama Menginap $=5$ hari

Kode Dokter $=$ DK003

\begin{tabular}{|l|l|l|}
\hline Kode Pasien & Status Pasien & Biaya Daftar Pasien \\
\hline PS0001 & Pasien Baru & Rp. 500.000 \\
\hline PS0002 & Pasien Lama & Rp. 400.000 \\
\hline PS0003 & Pasien BPJS & Rp. 300.000 \\
\hline PS0004 & Pasien Askes & Rp. 200.000 \\
\hline
\end{tabular}

\begin{tabular}{|l|l|l|}
\hline Kode Kamar & Nama Kamar & Biaya Kamar \\
\hline 1111 & Kamar Melati & Rp. 1.000 .000 \\
\hline 2222 & Kamar Mawar & Rp. 2.000 .000 \\
\hline 3333 & Kamar Dahlia & Rp. 3.000 .000 \\
\hline 4444 & Kamar Anggrek & Rp. 4.000 .000 \\
\hline 5555 & Kamar Tulip & Rp. 5.000.000 \\
\hline
\end{tabular}

\begin{tabular}{|l|l|l|}
\hline Kode Dokter & Nama Dokter & Biaya Pemeriksaan \\
\hline DK001 & DR. Andi & Rp. 500.000 \\
\hline DK002 & DR. Joko & Rp. 400.000 \\
\hline DK003 & DR. Karni & Rp. 300.000 \\
\hline DK004 & DR. Amin & Rp. 200.000 \\
\hline DK005 & DR. Udin & Rp. 100.000 \\
\hline
\end{tabular}

\begin{tabular}{|l|l|}
\hline Lama Menginap & Diskon \\
\hline$>10$ Hari & $50 \%$ dari Biaya Kamar \\
\hline$>8$ Hari & $40 \%$ dari Biaya Kamar \\
\hline$>6$ Hari & $30 \%$ dari Biaya Kamar \\
\hline$>4$ Hari & $20 \%$ dari Biaya Kamar \\
\hline$>+1$ & $10 \%$ dari Biaya Kamar \\
\hline
\end{tabular}

Total Bayar = Biaya Daftar Pasien + Biaya Kamar + Biaya Pemeriksaan - Diskon Output (Tampilkan) = 


\section{SOURCE CODE / KODING PROGRAM}

public class rawatinapRS \{

public static void main (String [] args)\{

//deklarasi variabel

String kode_pasien ="PS003";

String kode_dokter ="DK003";

int kode_kamar $=4444$;

int lama_inap $=5$;

String stts_pasien, nm_kamar, nm_dokter;

int biaya_daftar, biaya_kamar, biaya_pemeriksaan;

int totalBayar;

double diskon;

//deklarasi proses

if (kode_pasien.equals ("PS001"))\{

stts_pasien ="Pasien Baru";

biaya_daftar $=500000$;

\}

else if (kode_pasien.equals ("PSO02")) \{

stts_pasien ="Pasien Lama";

biaya_daftar $=400000$;

\}

else if (kode_pasien.equals ("PS003"))\{

stts_pasien ="Pasien BPJS";

biaya_daftar $=300000$;

\}

else if (kode_pasien.equals ("PS004"))\{

stts_pasien ="Pasien Akses";

biaya_daftar $=200000$;

\}

else\{

stts_pasien ="TIDAK DIKETAHUI";

biaya_daftar $=0$;

\}

if (kode_kamar==1111)\{

nm_kamar ="kamar Melati";

biaya_kamar =1000000;

\}

else if (kode_kamar==2222)

nm_kamar ="kamar Mawar";

biaya_kamar $=\mathbf{2 0 0 0 0 0 0}$;

\}

else if (kode_kamar==3333) \{

nm_kamar ="kamar Dahlia";

biaya_kamar $=3000000$;

\}

else if (kode_kamar $==4444$ )

nm_kamar ="kamar Anggrek";

biaya_kamar $=4000000$;

\}

else if (kode_kamar==5555)

nm_kamar ="kamar Tulip";

biaya_kamar $=5000000$;

\}

else\{

nm_kamar ="TIDAK DIKETAHUI"; 


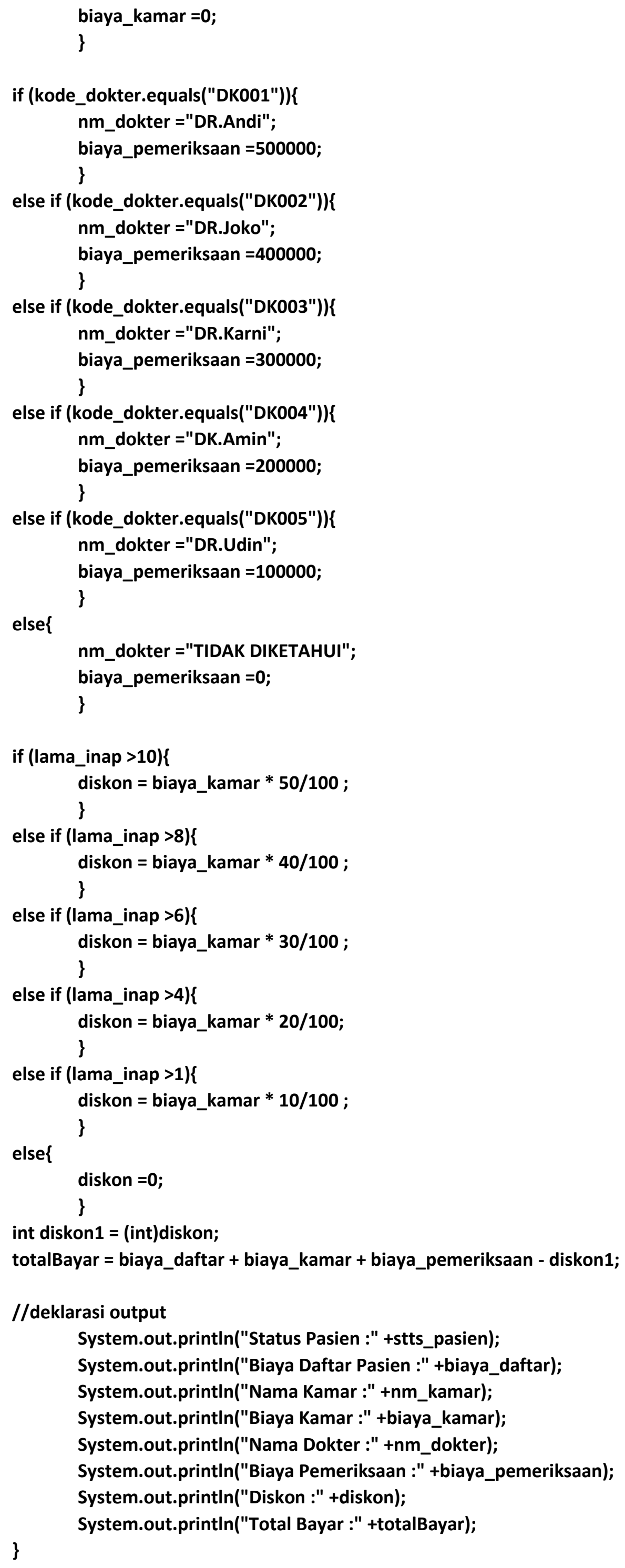




\section{PENJELASAN SOURCE CODE (KETIK DIBAWAH INI)}

\section{Public class}

Public class adalah sebuah lokasi dimana nantinya akan diakses oleh class. Public digunakan semua variabel dalam class, dan dapat diakses dari kelas manapun.

$>$ Public static void main (String [] args)

Merupakan langkah utama dalam java dalam memulai program. Syntaxnya selalu sama yaitu "public static void main (String [] args)"

\section{Deklarasi variabel}

Deklarasi variabel adalah proses memperkenalkan variabel yang akan digunakan, sifatnya muthlak. Gunanya menginformasikan tipe variabel yang digunakan.

Tipe-tipe variabel :

- String : tipe data yang menampilkan teks yang menggabungkan huruf dn angka.

- Int : tipe data yang menampilkan hanya bilangan bulat saja.

- Double : tipe data yang menampilkan bilangan pecahan.

\section{Deklarasi proses}

Deklarasi proses dapat didefinisikan sebagai proses pengisiian nilai. Pengisian nilai dilakukan dengan menggunakan operator. Seperti;

- If : dimana suatu opsi akan dijalankan sesuai dengan pilihan. Jika misal pilihannya " $y$ " makan perintah if akan dijalankan.

- Else

Kebalikannya yang if, misal perintah if "yes" maka masih ada pilihan. Sedangkan misal tidak sesuai perintah maka perintah yang dijalankan oleh "else"

Simbol-simbol yang digunakan dalam program java seperti petik dua (“”), titik koma (;), kurung kurawal (\{\}), plus (+), dan kurung biasa (). Sangat berpengaruh dalam proses jalannya program. Masing masing diantaranya digunakan untuk;

- Petik dua (“ ") : untuk memanggil variabel data yang tipenya string

- Titik koma (;) : diprogram java ; sangat berpengaruh dalam prosesnya, ketika salah codenya ada yang kurang tanda ; maka proses tersebut tidak jalan.

- Kurung kurawal (\{\}) : tanda ini menyatakan adanya pembukaan dan penutup dalam suatu proses

- Plus (+) : tanda plus (+) dibagian system.out.print gunanya untuk memanggil hasil yang akan ditampilkan

- Kurung biasa () : digunakan untuk pembuka dan penutup kondisi setelah penulisan if

\section{System.out.println}

Berfungsi untuk menampilkan output ke layar monitor.

Contah, misal ada perintah dibawah ini maka akan menghasilkan output sebagai berikut: 
//deklarasi output

System.out.println("Status Pasien :" +stts_pasien);

System.out.println ("Biaya Daftar Pasien :" +biaya_daftar);

System.out.println("Nama Kamar :" +nm_kamar);

System.out.println ("Biaya Kamar :" +biaya_kamar);

System.out.println("Nama Dokter :" +nm_dokter);

System.out.println ("Biaya Pemeriksaan :" +biaya_pemeriksaan);

System.out.println ("Diskon :" tdiskon);

System.out.println("Total Bayar :" +totalBayar);

C:4. C:IWindows lsystem $32 \backslash \mathrm{cmd}$.exe

Status Pasien :Pasien BPJS

Biaya Daftar Pasien : 30000

Nama Kamar : kamar Anggrek

Biaya Kamar : 4000000

Nama Dokter : DR. Karni

Biaya Pemeriksaan : 30000

Diskon :800000.0

Total Bayar : 38 gagag

Press any key to continue 


\section{FLOWCHART PROGRAM}

\section{START}

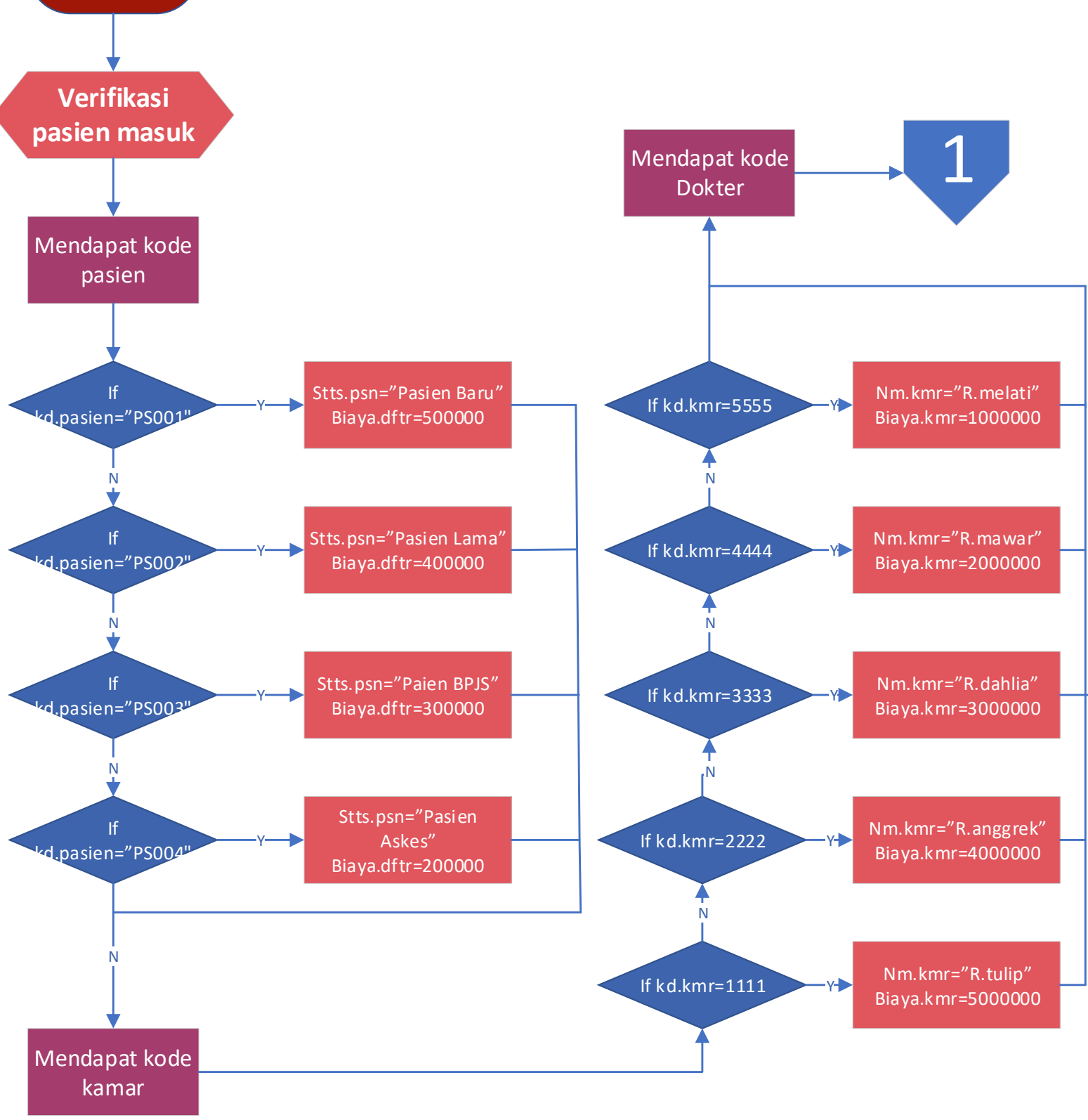




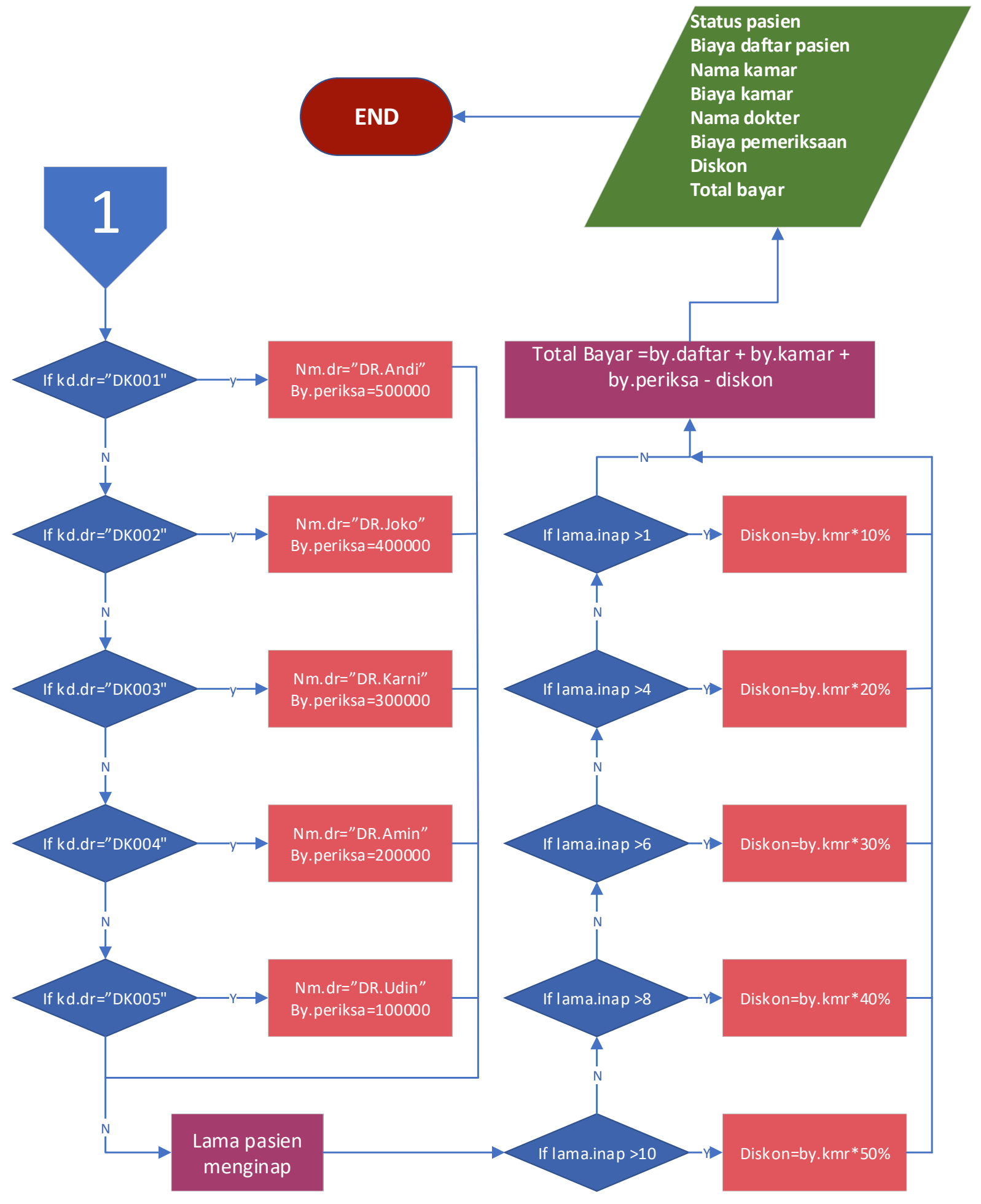


REFERENSI :

Endra, R. Y. (2019, October 29). Belajar Mudah Algoritma dan Pemograman Java. Retrieved from osf.io/v7yfn

Endra, R. Y. (2019, October 29). Internet of Things. Retrieved from osf.io/4h8sf 